\title{
A Novel and Simpler Alkaline Hydrolysis Methodology for Extraction of Ferulic Acid from Brewer's Spent Grain and its (Partial) Purification through Adsorption in a Synthetic Resin
}

\author{
Pedro Ideia ${ }^{1}$, Ivo Sousa-Ferreira ${ }^{2}$ and Paula C. Castilho ${ }^{1, *(1)}$ \\ 1 CQM-Centro de Química da Madeira, Universidade da Madeira, Campus da Penteada, 9020-105 Funchal, \\ Portugal; pedro.ideia@staff.uma.pt \\ 2 Centro de Estatística e Aplicações, Faculdade de Ciências, Universidade de Lisboa, 1749-016 Lisboa, \\ Portugal; ivo.ferreira@staff.uma.pt \\ * Correspondence: pcastilho@staff.uma.pt
}

Received: 25 March 2020; Accepted: 18 April 2020; Published: 8 May 2020 updates

\begin{abstract}
This work aims to develop simpler methodologies of extracting ferulic acid (FA) from brewer's spent grain (BSG). BSG is produced by brewing companies at high amounts all over the year and does not possess a direct application. Thus, its use as raw material for extraction of bioactive compounds has gained attention in the last years. FA has different interesting applications in cosmetics, food industry, and pharmaceutics. Several studies aim for its extraction from BSG by various methods, namely alkaline hydrolysis. In the present work, we suggest the use of autoclave to process higher amounts of BSG in a lab scale. A simplification of the regular post-hydrolysis procedures is also proposed to decrease the number of experimental steps and energy costs and to simultaneously increase the extraction yield (up to $470 \mathrm{mg}$ of FA per $100 \mathrm{~g}$ of BSG). The adsorption of extracted FA in a synthetic resin is suggested as a partial purification method.
\end{abstract}

Keywords: ferulic acid; brewer's spent grain; alkaline hydrolysis; adsorption; synthetic resin

\section{Introduction}

Due to the great political and social pressure in reducing pollution arising from industrial activities, large companies no longer consider residues as a waste but as valuable raw materials for other processes [1].

Brewer's spent grain (BSG) is the main solid by-product of brewing industry, produced during the wort elaboration step of beer production [1]. BSG is produced in a ratio of $20 \mathrm{~kg}$ per $100 \mathrm{~L}$ of beer [2], and the worldwide production is around 38.6 $\times 10^{6}$ tons/year [3]. Despite being commonly used for animal and even human feed [4-7], excessive BSG availability is gaining attention for other applications, among which are the production or the extraction of high value added compounds, namely oligosaccharides [8], xylitol [9,10], and ferulic acid (FA) [11-13], a phenolic compound belonging to the hydroxycinnamic acids family.

Due to its physiological functions - anti-oxidant, anti-inflammatory, anti-thrombosis anti-microbial, and anti-cancer-as well as its protective effect against coronary disease, FA is considered one of the most important phenolic compounds [14]. Several applications are described, such as vanillin production [15], as preservatives [16,17], and as an ingredient for dermatologic lotions [14], among others. Because FA is covalently linked to the structure of lignocellulosic biomass by ether and ester bonds, conventional extraction techniques (e.g., solid-liquid extraction) are not effective in its separation from the matrix. Other techniques, such as alkaline hydrolysis, are needed in order to cleave these bonds and release FA. 
In fact, alkaline hydrolysis is able to cleave the lignin/phenolic-carbohydrate complexes structure, resulting in a phenolic portion, soluble sugars, insoluble lignin, and carbohydrates [18]. Other methods such as enzymatic hydrolysis were developed to recover ferulic acid from lignocellulosic biomass, namely wheat bran $[19,20]$. The main disadvantages of enzymatic hydrolysis are the cost of enzymes and/or the reaction time. Additionally, for the process to be efficient, control of reaction temperature and $\mathrm{pH}$ is required.

Different procedures for alkaline hydrolysis reactions are described in literature, namely those reported by Mussatto et al. (2007) [11] and McCarthy et al. (2013) [6]. The most common is to perform the reaction into auto-pressurized tubes or cylindrical stainless steel reactors at high temperatures and high pressures. Moreia and co-workers $[13,21]$ suggested using microwave assisted extraction (MAE) to promote FA release from lignocellulosic materials, such as BSG. Despite the short time required for extraction, MAE's main limitation is the small amount of BSG the system is able to process in each batch. The present work aimed to optimize FA extraction from BSG by the simplification of the methods described in literature, which resulted in reducing the time and the resources required for extraction. Additionally, extraction in an autoclave allows one to scale-up the FA extraction, bridging the limitations of other processes already described.

Currently, adsorption technology is widely used for the removal of organic compounds from aqueous solutions and heterogeneous mixtures. The main disadvantage associated with the most used adsorbents is the high regeneration cost. This has stimulated the research on new adsorbents such as macrobead synthetic resins, which may provide a cheap and effective chemical regeneration process [22].

Several authors refer to the adsorption of ferulic acid in resins such as Amberlite XAD-16 [23] or Lewatit-type resins [24], aiming at its purification. These last authors studied three different

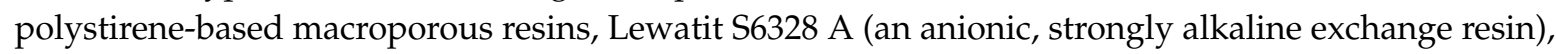
Lewatit S2328 (food grade cationic exchange, strongly acidic), and Lewatit S7968, a resin without functional groups, which gave the best performance on the adsorption of chlorogenic acids from artichoke residues with little sugar co-adsorption. A similar resin Lewatit VPOC1064 was chosen for purification of the extracted FA in the present work.

Our goal in this work was to use the principles of methods already reported and simplify the processes for cleaning as well as partially purify the FA extracted from BSG.

\section{Materials and Methods}

\subsection{Chemicals and Reagents}

All reagents and standards were of analytical reagent (AR) grade. Folin-Ciocalteu reagent, gallic acid (99\%), and sodium hydroxide (98\%) were purchased from Panreac (Madrid, Spain). Ferulic acid (99\%) and sodium carbonate (99.8\%) were from Sigma-Aldrich (St. Louis, MO, USA). Absolute ethanol was obtained from Riedel-de Haën, acetonitrile (99.9\%) from Fisher Scientific, and formic acid ( $\geq 98 \%)$ from Sigma-Aldrich. Synthetic resin (Lewatit VPOC1064 MD PH ${ }^{\circledR}$ ) was purchased from LANXESS (Köln, Germany).

Dimethylsulfoxid- $\mathrm{d}_{6}\left(\right.$ DMSO- $\left._{6}\right)(\geq 99 \%)$ was purchased from Merck (Darmstadt, Germany).

\subsection{Raw Material}

Brewer's spent grain (BSG) was provided by a local brewing company (ECM, Empresa de Cervejas da Madeira). The samples were freeze-dried immediately after delivery to our laboratory (NatLab-CQM). Dry BSG was stored at $-20^{\circ} \mathrm{C}$ until use. These samples were used throughout the work with the simple designation of "BSG". A sample of fresh BSG was used for moisture and ash content determinations. 


\subsection{Physicochemical Characterization}

The moisture content determination was carried out on a KERN DBS 60-3 moisture balance running a semi-automatic program, which heats the sample at $120{ }^{\circ} \mathrm{C}$ until the moisture content is stable for $30 \mathrm{~s}$. Ash content (\%) was determined after incineration of BSG samples in a muffle furnace at $\left(500{ }^{\circ} \mathrm{C}\right.$ for $\left.24 \mathrm{~h}\right)$. Particle size distribution was studied by passing three freeze-dried BSG portions though a set of sieves with decreasing mesh size $(1.0,0.5,0.25$ and $0.125 \mathrm{~mm})$.

\subsection{Alkaline Hydrolysis-Basic Procedure}

Alkaline hydrolysis was performed according to the procedure outlined in Figure $1 \mathrm{~A}$ and described in literature. Reactions were performed in Ace pressure tubes using BSG and $\mathrm{NaOH}$ solution in a solid:liquid ratio of 1:20 (w/v). Experimental conditions were optimized and set as $120^{\circ} \mathrm{C}$ for $1.5 \mathrm{~h}$ with $20 \mathrm{~mL}$ of $\mathrm{NaOH}(2 \%)$ for $1 \mathrm{~g}$ of BSG. Optimization was performed by individual variation of each of the extraction parameters.
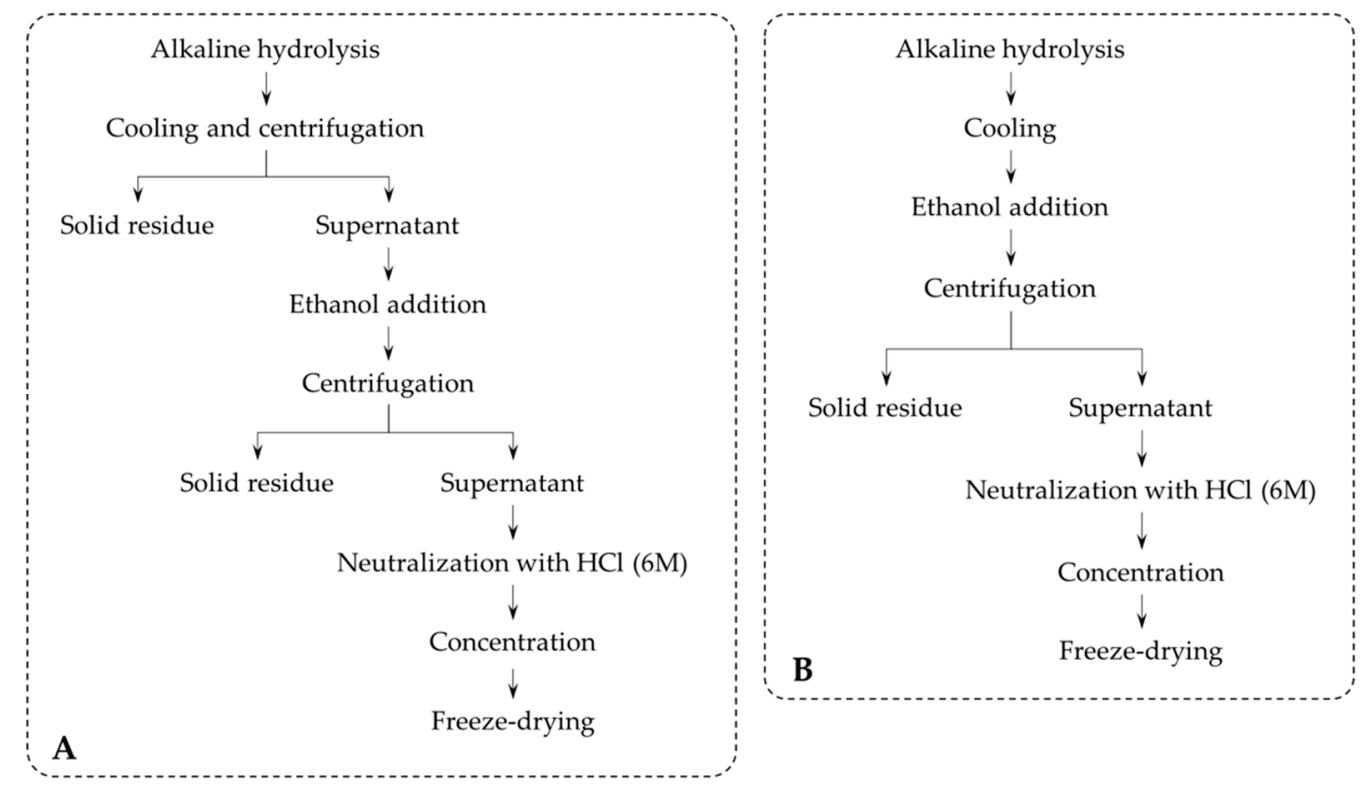

Figure 1. Proceeding to the alkaline hydrolysis reaction. (A) classic procedure; (B) simplified methodology.

The tubes were placed into an oil bath and heated. After alkaline hydrolysis reaction, the mixture was cooled to room temperature, and the solid residue, containing mainly cellulose and lignin, was separated by centrifugation. Precipitation of the hemicellulose fraction was triggered by addition of ethanol to a final concentration of $30 \%(v / v)$, and its separation was performed by centrifuging. The supernatant, which contained the ferulic acid, was neutralized with $\mathrm{HCl}(6 \mathrm{M})$ and concentrated on a rotary evaporator. The aqueous phase was freeze-dried and stored at $-20{ }^{\circ} \mathrm{C}$ until analysis.

\subsection{Pretreatment by Solid-Liquid Extraction with Acetone}

A portion of BSG was extracted with acetone $(60 \%)$ in a solid/liquid ratio of $50 \mathrm{~mL} / \mathrm{g}$ in an ultrasound bath for $1 \mathrm{~h}$. After solid-liquid extraction, the mixture was allowed to cool to room temperature, and the solid residue was separated from the supernatant by centrifugation followed by filtration. The solid residue was washed with distilled water and freeze-dried. Alkaline hydrolysis was carried out in Ace tubes at $120^{\circ} \mathrm{C}$ for $1.5 \mathrm{~h}$ with $20 \mathrm{~mL}$ of $\mathrm{NaOH}(2 \%)$ for $1 \mathrm{~g}$ of BSG. For comparison, a portion of BSG not subjected to pretreatment was extracted by alkaline hydrolysis in the same conditions. 


\subsection{Extraction by Alkaline Hydrolysis in Autoclave}

An alkaline hydrolysis assay was carried under the same conditions $\left(120^{\circ} \mathrm{C}\right.$ for $1.5 \mathrm{~h}$ with $20 \mathrm{~mL}$ of $\mathrm{NaOH}(2 \%)$ for $1 \mathrm{~g}$ of $\mathrm{BSG})$ in autoclave. The subsequent procedure was similar to that described for Ace tubes. The resultant extracts were stored at $-20^{\circ} \mathrm{C}$ until analysis.

\subsection{Simplification of the Procedure}

A modification of the process described in the literature was introduced in order to diminish the number of separation steps and thus improve the yield in the desired product; after alkaline hydrolysis, the mixture was cooled, and ethanol was added (Figure 1B). Precipitated hemicellulose was separated by centrifugation together with lignin and cellulose fraction. The supernatant was neutralized, concentrated, and the aqueous phase was freeze-dried and stored at $-20{ }^{\circ} \mathrm{C}$ until analysis.

\subsection{Analysis of Extracts}

The extracts obtained after the procedures described in the previous sections were analyzed in terms of their total soluble solids (TSS), total phenolic content (TPC), and quantification of ferulic acid by HPLC-diode-array detector (DAD).

\subsubsection{Total Soluble Solids (TSS) Determination}

For TSS determinations [25], extracts were resuspended in water $(10 \mathrm{mg} / \mathrm{mL})$ and filtered through membrane filters $(0.45 \mu \mathrm{m})$. Using an ATAGO RX-1000 refractometer, the TSS was measured based on a calibration curve of sucrose $(5-50 \mathrm{mg} / \mathrm{L})$. The results are expressed in milligrams of sucrose equivalent (SE) per $100 \mathrm{~g}$ of dry BSG.

\subsubsection{Total Phenolic Content (TPC) Determination}

TPC was determined by Folin-Ciocalteu method [26]; fifty microliters of the sample in methanol $\left(5 \mathrm{mg} / \mathrm{mL}\right.$ ) was mixed with $1.25 \mathrm{~mL}$ of Folin-Ciocalteu solution (1:10) and $1 \mathrm{~mL}$ of $\mathrm{Na}_{2} \mathrm{CO}_{3}(7.5 \%)$. The absorbance at $765 \mathrm{~nm}$ was measured after $30 \mathrm{~min}$, and results were expressed as milligrams of gallic acid equivalent (GAE) per $100 \mathrm{~g}$ of BSG (dry weight).

\subsubsection{Quantification of Ferulic Acid}

Ferulic acid concentrations were determined by high performance liquid chromatography (HPLC) using a UV detector (at $320 \mathrm{~nm})$ and a Phenomenex Gemini C18 $(5 \mu \mathrm{m}, 250 \times 0.3 \mathrm{~mm}$ i.d.) column. The HPLC analysis, adapted from Gouveia and Castilho (2011) [26], was performed on a Dionex ultimate 3000 series instrument (Dionex, Sunnyvale, CA, USA) coupled to a binary pump, a diode-array detector (DAD), an autosampler and a column compartment. Samples $(5 \mathrm{mg} / \mathrm{mL})$ were prepared in the mobile phase and filtered through $0.45 \mu \mathrm{m}$ membranes (Millipore, Burlington, MA, USA). Then, samples were injected into the equipment under the following conditions: column at $30{ }^{\circ} \mathrm{C}$, acetonitrile/0.1\% formic acid as mobile phase (isocratic elution, 75:25), a flow rate of $400 \mu \mathrm{L} / \mathrm{min}$, and injection volume of $10 \mu \mathrm{L}$. Results are expressed as mg of FA per $100 \mathrm{~g}$ of BSG (dry weight).

Identification was performed comparing retention times with those obtained from commercial ferulic acid standard. Quantification was based on the UV signal response at $320 \mathrm{~nm}$, and the resultant peak areas in the chromatograms were plotted against concentrations obtained from standard. Calibration curve $(5-100 \mathrm{mg} / \mathrm{L})$ was prepared by diluting the stock solutions ( $1000 \mathrm{mg} / \mathrm{L}$ in methanol) with the initial mobile phase. Quantification was carried out by plotting peak area versus concentration $\left(R^{2}=0.9994\right)$.

\subsubsection{Statistical Analysis}

All samples were assayed in triplicate $(n=3)$, and results are given as means \pm standard deviations. Differences between means were tested by ANOVA using SPSS Statistics 22 software. 


\subsection{Purification by Adsorption on a Synthetic Resin}

Synthetic resin (Lewatit VPOC1064 MD PH ${ }^{\circledR}$ ) was used to promote adsorption of FA from the extract obtained after alkaline hydrolysis using the simplified method previously described (Figure 1B).

\subsubsection{Kinetic Studies with FA Standard}

Before purification of alkaline hydrolysis extract, adsorption kinetic studies with FA standard were performed. During these studies, several conditions were tested in three different assays. In the first assay, a proportional variation of FA concentration and the amount of adsorbent were carried up within three different tests. A second assay was achieved in two tests, where different initial concentrations of FA were studied. Finally, in the third assay, the effect of temperature in the adsorption was evaluated. Two tests were performed at room temperature $\left(22-25^{\circ} \mathrm{C}\right.$ ) and $6{ }^{\circ} \mathrm{C}$ (controlled ice bath), respectively. Table 1 resumes the conditions of the different assays.

Table 1. Conditions of the adsorption mixtures during in adsorption kinetic studies. The volume of ferulic acid (FA) solution used in each teste was constant $(50 \mathrm{~mL})$.

\begin{tabular}{ccccc}
\hline Assay & Test & {$[$ FA] $(\mathrm{g} / \mathrm{L})$} & Resin wt. $(\mathrm{g})$ & Temperature \\
\hline \multirow{2}{*}{1} & $A d s A$ & 1 & 0.5 & \\
& $A d s B$ & 0.5 & 0.25 & Room temp. \\
& $A d s C$ & 0.25 & 0.125 & \\
\hline \multirow{2}{*}{2} & $A d s H C$ & 1 & 0.5 & Room temp. \\
& $A d s L C$ & 0.25 & 0.5 & Room temp. \\
\multirow{2}{*}{3} & $A d s R T$ & 0.25 & 0.5 & $6^{\circ} \mathrm{C}$ \\
\hline
\end{tabular}

A supernatant sample was collected every $2 \mathrm{~min}$ in the first $10 \mathrm{~min}$, every $10 \mathrm{~min}$ during the next $90 \mathrm{~min}$, and every $20 \mathrm{~min}$ until $180 \mathrm{~min}$ of adsorption. After filtration of supernatants, FA concentration was determined. Adsorption percentage, the amount of $\mathrm{FA}$ adsorbed per gram of resin, and $C / C_{0}$ were used to evaluate the adsorption process.

The equation below was applied to the experimental data, and the parameters $\alpha, \beta, \gamma, \delta$ and $\theta$ were determined using the Solver Microsoft Excel add-in program.

$$
\frac{C}{C_{0}}=\alpha+\beta \cdot e^{-\frac{t}{\gamma}}+\delta \cdot e^{-\frac{t}{\theta}}
$$

where $C_{0}$ is the initial concentration of the absorbate $(\mathrm{g} / \mathrm{L})$, and $C$ is the concentration at the time $t(\mathrm{~g} / \mathrm{L})$.

\subsubsection{Purification of an Alkaline Hydrolysis Extract}

As outlined in Figure 2, a portion of $2 \mathrm{~g}$ of alkaline hydrolysis freeze dried extract was dissolved in $40 \mathrm{~mL}$ of water at $40^{\circ} \mathrm{C}$ with vigorous stirring. After cooling the mixture to room temperature, a portion of $10 \mathrm{~g}$ of pre-activated resin (according to the supplier, treatment with $6 \% \mathrm{HCl}$ and $4 \%$ $\mathrm{NaOH}$ and washing with distilled water) was added to the flask. The mixture was magnetically stirred for $2 \mathrm{~h}$ and filtered under reduced pressure. The filtrate was used to determine the FA adsorption yield, and the loaded resin was further stirred with $50 \mathrm{~mL}$ of ethanol:water $(70 \%)$ in order to promote desorption. A new filtration allowed us to separate the resin from the liquid phase containing the FA. The determination of desorbed FA was possible through analysis of the filtrate. 


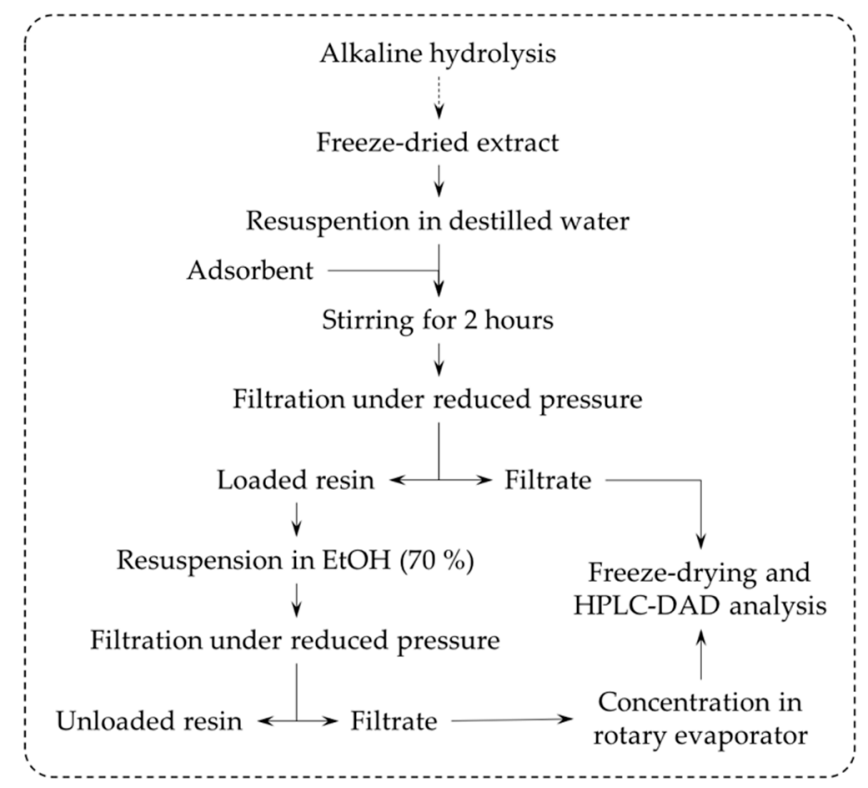

Figure 2. Procedure for the partial purification of FA by adsorption on a synthetic resin.

The extracts were analyzed in terms of FA quantification by HPLC-DAD according to the conditions mentioned before. ${ }^{1} \mathrm{H}$ NMR was performed to verify the partial purification of the extract obtained by alkaline hydrolysis of BSG and treated with the Lewatit resin. For NMR analysis, $10 \mathrm{mg}$ of each extract were dissolved in $1 \mathrm{~mL}$ of DMSO- $\mathrm{d}_{6}$ and transferred to $5 \mathrm{~mm}$ NMR tubes. ${ }^{1} \mathrm{H}$ spectra were recorded on a Bruker UltraShield 400 Plus NMR (Bruker, Billerica, MA, USA) at 10,061 MHz and $400 \mathrm{MHz}$. Acquisition parameters for ${ }^{1} \mathrm{H}$ were: size of fit 65 k; spectral width $4401 \mathrm{~Hz}$; acquisition time 64 k; relaxation delay 1 s; number of scans 512.

\section{Results and Discussion}

\subsection{Physicochemical Characterization of BSG}

The moisture content of supplied BSG was $68.44 \pm 0.93 \%$, and the ash content was $4.18 \pm 0.03 \%$. Sifting of freeze-dried material revealed that BSG was provided as a fine powder with particle size between 1 and $0.25 \mathrm{~mm}$ (Table 2), and it was further used without any separation.

Table 2. Particle size distribution.

\begin{tabular}{ccccc}
\hline Particle Size (mm) & \multicolumn{4}{c}{ Percentage } \\
\hline$>1$ & 3.83 & \pm & 0.37 \\
$1-0.5$ & 36.00 & \pm & 1.48 \\
$0.5-0.25$ & 41.06 & \pm & 2.44 \\
$0.25-0.125$ & 12.57 & \pm & 2.65 \\
$\leq 0.125$ & 6.76 & \pm & 1.12 \\
\hline
\end{tabular}

\subsection{Optimization of Alkaline Hydrolysis Conditions}

Table 3 summarizes the results for optimization of alkaline hydrolysis reaction in Ace pressure tubes. Different reaction temperatures $\left(60,80,100\right.$, and $\left.120^{\circ} \mathrm{C}\right)$ were tested for $1 \mathrm{~h}$ with $\mathrm{NaOH}(2 \%)$. Reaction time ( 1 to $3 \mathrm{~h}$ ) was tested at $100{ }^{\circ} \mathrm{C}$ using $\mathrm{NaOH}(2 \%)$. Optimization of alkali solution concentration was performed in reactions at $100{ }^{\circ} \mathrm{C}$ for $1 \mathrm{~h}$. Optimal conditions were set as $120{ }^{\circ} \mathrm{C}$ for $1.5 \mathrm{~h}$ with $20 \mathrm{~mL}$ of $\mathrm{NaOH}(2 \%)$ for $1 \mathrm{~g}$ of BSG. 
Table 3. Conditions and results obtained for optimization of the parameters for alkaline hydrolysis reaction in Ace pressure tubes. FA yield is expressed as mg of FA per $100 \mathrm{~g}$ of brewer's spent grain (BSG).

\begin{tabular}{cccccc}
\hline Temp. $\left({ }^{\circ} \mathbf{C}\right)$ & Time (Hours) & NaOH $(\%)$ & \multicolumn{2}{c}{ FA Yield (mg FA/100 g) } \\
\hline 60 & 1 & 2 & 46.95 & \pm & 9.72 \\
80 & 1 & 2 & 81.52 & \pm & 17.89 \\
100 & 1 & 2 & 214.18 & \pm & 30.43 \\
120 & 1 & 2 & 234.98 & \pm & 8.03 \\
\hline 100 & 1 & 2 & 214.67 & \pm & 4.70 \\
100 & 1.5 & 2 & 223.97 & \pm & 6.82 \\
100 & 2 & 2 & 223.05 & \pm & 1.47 \\
100 & 2.5 & 2 & 202.62 & \pm & 19.65 \\
100 & 3 & 2 & 223.09 & \pm & 17.85 \\
\hline 100 & 1 & 0.5 & 174.76 & \pm & 23.64 \\
100 & 1 & 1 & 199.63 & \pm & 11.21 \\
100 & 1 & 1.5 & 214.53 & \pm & 23.26 \\
100 & 1 & 2 & 204.44 & \pm & 9.64 \\
100 & 1 & 2.5 & 200.10 & \pm & 22.07 \\
\hline
\end{tabular}

\subsection{Pretreatment by Solid-Liquid Extraction with Acetone}

The results compiled in Table 4 reveal that extraction with acetone is effective in removing free sugars from the matrix, resulting in a significant decrease in TSS for pretreated BSG compared with the untreated portion. FA concentration in the extracts obtained by alkaline hydrolysis of both untreated and pretreated BSG portions did not show a statistically significant difference. Results obtained in previous works [27] showed that solid-liquid extraction with $60 \%$ acetone is efficient in the extraction of free form compounds from BSG. The present data show that solid-liquid extraction is not efficient in the extraction of FA from lignocellulosic materials, since it is covalently bonded to their structure, but soluble solids such as mono and disaccharides are partially removed.

Table 4. Comparison of the results obtained for alkaline hydrolysis of not pretreated and treated BSG $(1 \mathrm{~h})$. Total soluble solids (TSS) is expressed as mg of sucrose equivalent per $100 \mathrm{~g}$ of BSG, total phenolic content (TPC) is expressed as gram of gallic acid equivalent per $100 \mathrm{~g}$ of BSG, and FA yield is expressed as $\mathrm{mg}$ of FA per $100 \mathrm{~g}$ of BSG.

\begin{tabular}{ccccccc}
\hline & \multicolumn{2}{c}{ Not Pretreated } & \multicolumn{2}{c}{ Pretreated } \\
\hline $\begin{array}{c}\text { TSS } \\
\text { mg SE/100 g }\end{array}$ & 94.50 & $\pm 8.39^{\mathrm{a}}$ & 69.39 & $\pm 3.28^{\mathrm{b}}$ \\
\hline $\begin{array}{c}\text { TPC } \\
\text { g GAE/100 g }\end{array}$ & 1010.44 & \pm & $1.58^{\mathrm{a}}$ & 1323.24 & $\pm 143.30^{\mathrm{b}}$ \\
\hline $\begin{array}{c}\text { FA yield } \\
\text { mg FA/100 g }\end{array}$ & 259.21 & $\pm 35.95^{\mathrm{a}}$ & 270.32 & $\pm 65.86^{\mathrm{a}}$
\end{tabular}

${ }^{a}$ indicates not significant differences and ${ }^{b}$ indicates significant differences. SE: sucrose equivalent; GAE: gallic acid equivalent.

\subsection{Extraction by Alkaline Hydrolysis in Autoclave}

The characterization of the extracts (Table 5) showed that differences on TSS were not significant. However, there was a statistically significant increase of TPC and FA yield for those obtained by alkaline hydrolysis in autoclave compared to those obtained in Ace pressure tubes. This might have been due to a higher contact exchange between BSG and alkali solution in autoclave, resulting from the greater volume of the reaction vessels in which hydrolysis was performed. Taking into account the aspects mentioned above, alkaline hydrolysis of BSG in an autoclave might be an interesting process 
for a possible scale-up of the extraction process, since even everyday laboratory equipment is capable of processing large amounts of BSG.

Table 5. Comparison of the results obtained for alkaline hydrolysis on Ace pressure tubes and in an autoclave (1.5 h). TSS is expressed as mg of sucrose equivalent per $100 \mathrm{~g}$ of BSG, TPC is expressed as gram of gallic acid equivalent per $100 \mathrm{~g}$ of BSG, and FA yield is expressed as mg of FA per $100 \mathrm{~g}$ of BSG.

\begin{tabular}{ccccccc}
\hline & \multicolumn{3}{c}{ Ace Pressure Tubes } & \multicolumn{2}{c}{ Autoclave } \\
\hline $\begin{array}{c}\text { TSS } \\
\text { mg SE/100 g }\end{array}$ & 81.45 & $\pm 2.59^{\mathrm{a}}$ & 82.44 & $\pm 9.17^{\mathrm{a}}$ \\
\hline $\begin{array}{c}\text { TPC } \\
\text { g GAE/100 g }\end{array}$ & 1194.20 & $\pm 21.34^{\mathrm{a}}$ & 1439.73 & $\pm 102.02^{\mathrm{b}}$ \\
\hline $\begin{array}{c}\text { FA yield } \\
\text { mg FA/100 g }\end{array}$ & 203.41 & $\pm 5.37^{\mathrm{a}}$ & 280.61 & $\pm 5.77^{\mathrm{b}}$ \\
\hline
\end{tabular}

${ }^{a}$ indicates not significant differences and ${ }^{b}$ indicates significant differences.

\subsection{Simplification of the Procedure}

Table 6 shows the results for the simplification of the procedure after alkaline hydrolysis in comparison with the normal procedure (schematized in Figure 1). Both TSS and TPC showed a large increase (of about $30.9 \%$ for TSS and $122.97 \%$ for TPC). FA yield was increased in about $80 \%$ with the change of procedure, up to $476.99 \pm 25.94 \mathrm{mg}$ (FA)/100 $\mathrm{g}$ (BSG, dry weight). The increase was probably due to the solvent washing during the addition of the ethanol to the alkaline liquor, which resulted in reduction of losses associated with the process. Thus, in addition to reducing the experimental steps and the energetic resources required for extraction, simplification of the procedure also permits obtaining a greater amount of FA. TSS increase may be an indication that larger carbohydrates are degraded into smaller, soluble sugar molecules.

Table 6. Comparison of the results obtained for normal and simplified procedures applied after alkaline hydrolysis. TSS is expressed as mg of sucrose equivalent per $100 \mathrm{~g}$ of BSG, TPC is expressed as gram of gallic acid equivalent per $100 \mathrm{~g}$ of BSG, and FA yield is expressed as mg of FA per $100 \mathrm{~g}$ of BSG.

\begin{tabular}{|c|c|c|c|c|c|c|}
\hline \multirow[b]{2}{*}{$\begin{array}{c}\text { TSS } \\
\mathrm{mg} \mathrm{SE} / 100 \mathrm{~g}\end{array}$} & \multicolumn{3}{|c|}{ Normal Procedure } & \multicolumn{3}{|c|}{ Simplified Procedure } \\
\hline & 94.50 & \pm & $8.39^{a}$ & 123.70 & \pm & $1.47^{\mathrm{b}}$ \\
\hline $\begin{array}{c}\text { TPC } \\
\text { g GAE/100 g }\end{array}$ & 1483.72 & \pm & $90.03^{a}$ & 3342.86 & \pm & $71.21^{b}$ \\
\hline $\begin{array}{c}\text { FA yield } \\
\text { mg FA/100 g }\end{array}$ & 259.21 & \pm & $35.95^{\mathrm{a}}$ & 476.99 & \pm & $25.94^{\mathrm{b}}$ \\
\hline
\end{tabular}

\subsection{Purification by Adsorption on a Synthetic Resin}

\subsubsection{Kinetic Studies with FA Standard}

Three assays were performed to study the adsorption kinetics under different experimental conditions, according to Table 1.

After determination of FA concentration in the various supernatant samples, $C / C_{0}$ was calculated for each time $t$, and parameters $\alpha, \beta, \gamma, \delta$ and $\theta$ were determined.

Figure 3 resumes the evolution of $C / C_{0}$ along the $180 \mathrm{~min}$ of adsorption in the different assays. Figure 3 a is related to assay 1 , where dispersion of both FA and resin increased in proportion within the tests $A d s A, A d s B$, and $A d s C$. Adsorption isotherms show that the variation in the concentration of adsorbed FA during the equilibrium was proportional to the dispersion of both adsorbate and adsorbent 
in the mixture. Assay 2 (Figure 3b) was performed to study the effect of the initial concentration of FA in the adsorption process. The FA concentration in test $A d s H C$ was four times higher than that in test AdsLC. Because the amount of resin was similar in both tests, isotherms indicated a more efficient adsorption process for $A d s L C$. Regarding the study of the effect of temperature in the adsorption process, Figure $3 \mathrm{c}$ resumes the results obtained under room temperature $(A d s R T)$ and $6{ }^{\circ} \mathrm{C}(A d s T 6)$. Results showed that, at room temperature, the equilibrium was achieved faster than at $6^{\circ} \mathrm{C}$. In all tests, it was possible to establish that $100-120 \mathrm{~min}$ is enough to reach equilibrium.

\section{(a)}

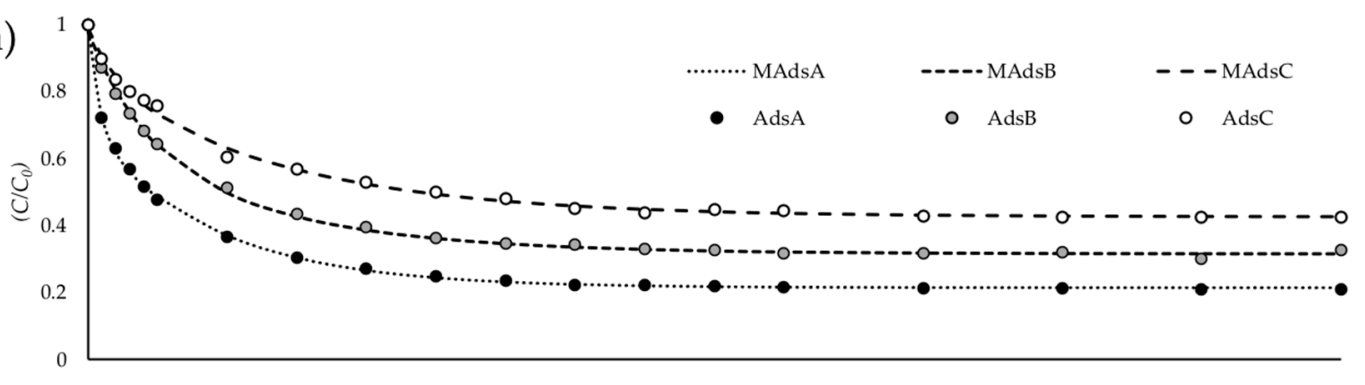

(b)

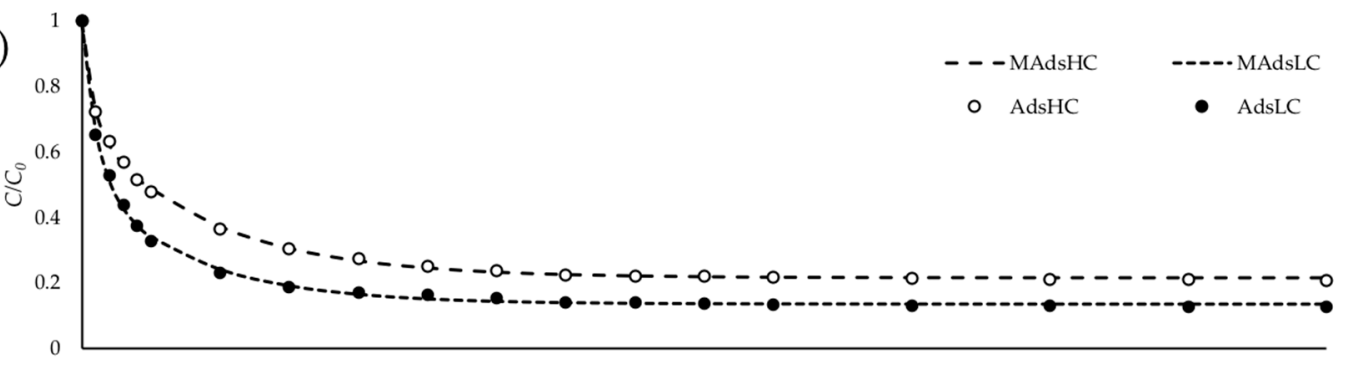

(c)

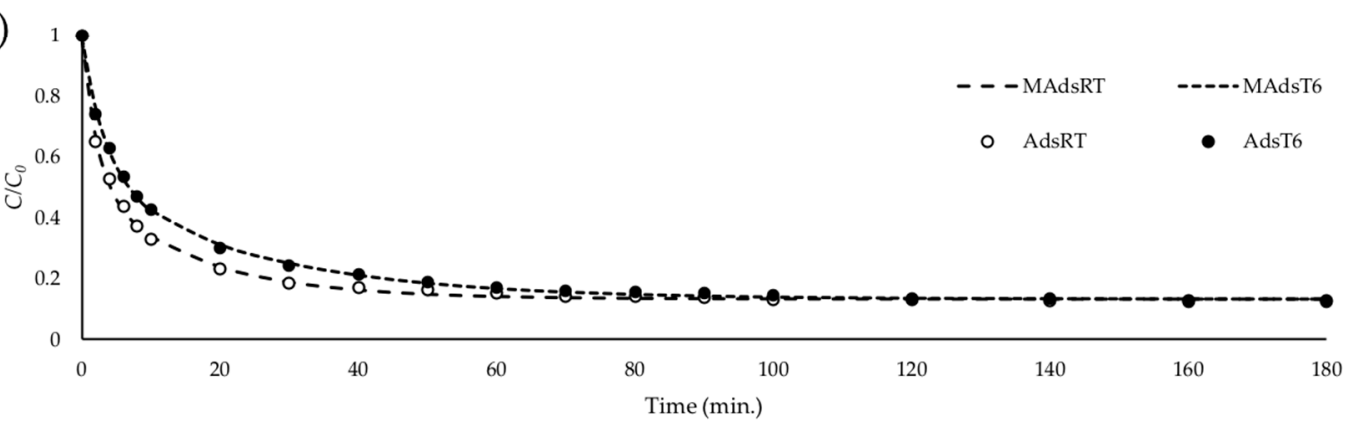

Figure 3. Adsorption kinetic isotherms for the assays performed to study the effect of (a) dispersion of FA and resin, (b) the initial concentration of FA, and (c) the temperature in the adsorption mixture.

Parameters for adsorption isotherms equations were determined and compiled in Table 7. Based on kinetic studies results, the best conditions for adsorption of FA standard may be an intermediate between the conditions of assays $A d s A, A d s L C$, and $A d s R T$. For real samples, where the goal is to purify FA from a variety of compounds of different chemical nature, the ideal conditions might be different, namely because of the competition for adsorption in the resin. 
Table 7. Determination of parameter estimates and sum of squared differences (SSD) by MS Solver for adjustment of adsorption kinetic curves.

\begin{tabular}{cccccccc}
\hline \multirow{2}{*}{ Assay } & \multirow{2}{*}{ Test } & \multicolumn{7}{c}{ Parameter } & \multirow{2}{*}{ SSD } \\
\cline { 3 - 7 } & & $\boldsymbol{\alpha}$ & $\boldsymbol{\beta}$ & $\boldsymbol{\gamma}$ & $\boldsymbol{\delta}$ & $\boldsymbol{\theta}$ & \\
\hline \multirow{3}{*}{$\mathbf{1}$} & AdsA & 0.2144 & 0.4721 & 18.1123 & 0.3122 & 1.6490 & 0.0006 \\
& AdsB & 0.3169 & 0.3620 & 24.1647 & 0.3031 & 7.9226 & 0.0014 \\
& AdsC & 0.4262 & 0.4271 & 27.1620 & 0.1391 & 4.1121 & 0.0022 \\
\hline \multirow{2}{*}{$\mathbf{2}$} & AdsHC & 0.2144 & 0.4721 & 18.1123 & 0.3122 & 1.6490 & 0.0006 \\
& AdsLC & 0.1343 & 0.3759 & 15.7397 & 0.4861 & 2.2909 & 0.0014 \\
\hline \multirow{2}{*}{3} & AdsRT & 0.1343 & 0.3759 & 15.7401 & 0.4861 & 2.2910 & 0.0014 \\
& AdsT6 & 0.1335 & 0.3992 & 24.5310 & 0.4604 & 3.4751 & 0.0013 \\
\hline
\end{tabular}

\subsubsection{Purification of an Alkaline Hydrolysis Extract}

Adsorption of FA from the alkaline hydrolysis extract showed to be effective $(90.83 \%)$, where around 4.6 milligrams of compound were adsorbed into the resin. The desorption was achieved by adding two portions of $25 \mathrm{~mL}$ of $70 \%$ ethanol followed by continuous stirring for $30 \mathrm{~min}$ and filtration. The filtrates were combined, concentrated, and the concentration of FA was determined by HPLC-DAD. Results showed that $68.70 \%$ of the adsorbed FA was desorbed under these conditions, indicating that about 1.4 milligrams of FA remained adsorbed.

${ }^{1} \mathrm{H}$ NMR spectra (Figure 4) suggests a partial purification of the extract obtained by alkaline hydrolysis of BSG in an autoclave and a simplified procedure. Figure 4A corresponds to FA standard spectrum. FA peaks were identified in both Figures $4 \mathrm{~B}$ and $4 \mathrm{C}$ for initial and partially purified extracts, respectively. Because FA concentration increased after purification, the peaks between 6.3 and $7.5 \mathrm{ppm}$ and the peak at $3.8 \mathrm{ppm}$ slightly increased in the final extract when compared to the original extract. On the contrary, peaks at 8.4 and $5.3 \mathrm{ppm}$ as well as regions 3.5 to $3.7,3.0$ to $3.4,2.6$ to $2.8,1.5$ to 2.3, and 1.0 to $1.3 \mathrm{ppm}$ decreased in the final extract compared with the initial extract. This suggests a decrease in the concentration of these compounds after partial purification with synthetic resin. 


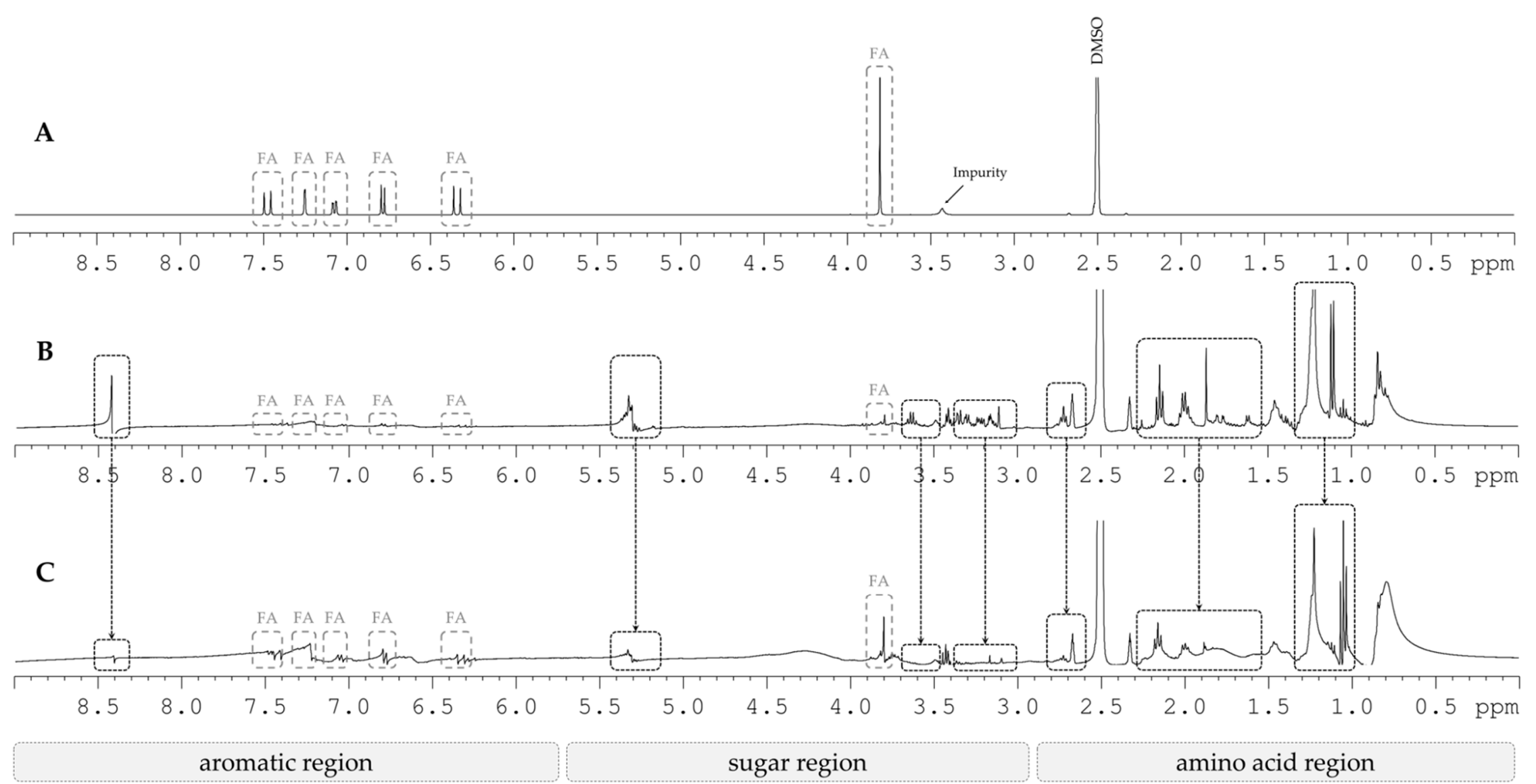

Figure 4. ${ }^{1} \mathrm{H}$ NMR spectra for (A) ferulic acid standard, (B) initial extract obtained by alkaline hydrolysis of BSG in autoclave with simplified post-extraction process and $(C)$ final extract partially purified by adsorption/desorption in the Lewatit resin. Peaks corresponding to ferulic acid are marked in a grey box with the inscription "FA". The black boxes indicate the regions where the differences were more significant. The arrows make the correspondence between initial and final extracts. 


\section{Conclusions}

Because of its high availability and potential, several works are being developed around BSG. One of the interesting compounds present in the lignocellulosic structure of BSG is ferulic acid. Since FA is not extracted from the BSG matrix by conventional solid-liquid extraction methods, alternative techniques such as alkaline hydrolysis are often applied. The methods described in literature usually comprise a pretreatment step to remove compounds resulting from the brewing process. Alkaline hydrolysis is commonly followed by centrifugation, precipitation of hemicellulose fraction in the alkaline liquor, and neutralization. In the present work, the use of autoclave to perform the alkaline hydrolysis and a simplification of the post-extraction process were suggested and were shown to increase FA yield. The extraction in an autoclave resulted in an increase of FA extraction yield of around $38 \%$ when compared with the extraction in pressure tubes. An increase of about $84 \%$ in the extraction yield was achieved in a small scale extraction in pressure tubes when a simplification of the post-extraction process was applied. A partial purification by adsorption on a synthetic resin was also suggested, constituting a potential approach to obtain ferulic acid in a higher degree of purity.

During the studies, $p$-coumaric acid was co-extracted in molar proportion ( $p$-CA:FA) between 1:4 and 1:8, depending on the extraction conditions.

Author Contributions: Conceptualization: P.I. and P.C.C.; methodology; P.I. and P.C.C.; software; P.I. and I.S.-F.; validation; P.I. and I.S.-F: formal analysis: P.I. and I.S.-F; investigation: P.I. and P.C.C.; resources: P.C.C.; data curation: P.I., I.S.-F and P.C.C.: writing-original draft preparation, P.I. and P.C.C.; writing — review and editing: P.I., I.S.-F and P.C.C.; visualization: P.I.; supervision: P.C.C.; project administration: P.C.C.; funding acquisition: P.C.C. All authors have read and agreed to the published version of the manuscript.

Funding: This research was partially supported by FCT-Fundação para a Ciência e a Tecnologia with funds from the Portuguese Government, under de projects UIDB/00674/2020 (Centro de Química da Madeira) and UIDB/00006/2020 (Centro de Estatística e Aplicações). PI grant through the project M1420-01-0145-FEDER-000005-Centro de Química da Madeira-CQM+ (Madeira 14-20) is also acknowledged.

Acknowledgments: Authors acknowledge Empresa de Cervejas da Madeira for the supply of BSG samples.

Conflicts of Interest: The authors declare no conflict of interest.

\section{References}

1. Mussatto, S.I.; Dragone, G.; Roberto, I.C. Brewers' spent grain: Generation, characteristics and potential applications. J. Cereal Sci. 2006, 43, 1-14. [CrossRef]

2. Gupta, M.; Abu-Ghannam, N.; Gallaghar, E. Barley for brewing: Characteristic changes during malting, brewing and applications of its by-products. Compr. Rev. Food Sci. Food Saf. 2010, 9, 318-328. [CrossRef]

3. Mussatto, S.I. Brewer's spent grain: A valuable feedstock for industrial applications. J. Sci. Food Agric. 2014, 94, 1264-1275. [CrossRef] [PubMed]

4. Aliyu, S.; Bala, M. Brewer's spent grain: A review of its potentials and applications. Afr. J. Biotechnol. 2011, 10, 324-331. [CrossRef]

5. McCarthy, A.L.; O'Callaghan, Y.C.; Piggott, C.O.; FitzGerald, R.J.; O’Brien, N.M. Brewers' spent grain; bioactivity of phenolic component, its role in animal nutrition and potential for incorporation in functional foods: A review. Proc. Nutr. Soc. 2013, 72, 117-125. [CrossRef]

6. McCarthy, A.; O'Callaghan, Y.C.; Neugart, S.; Piggott, C.O.; Connolly, A.; Jansen, M.A.; Krumbein, A.; Schreiner, M.; Fitzgerald, R.J.; O'Brien, N.M. The hydroxycinnamic acid content of barley and brewers' spent grain (BSG) and the potential to incorporate phenolic extracts of BSG as antioxidants into fruit beverages. Food Chem. 2013, 141, 2567-2574. [CrossRef]

7. Kaur, V.I.; Saxena, P.K. Incorporation of brewery waste in supplementary feed and its impact on growth in some carps. Bioresour. Technol. 2004, 91, 101-104. [CrossRef]

8. Carvalheiro, F.; Esteves, M.P.; Parajó, J.C.; Pereira, H.; Gírio, F.M. Production of oligosaccharides by autohydrolysis of brewery's spent grain. Bioresour. Technol. 2004, 91, 93-100. [CrossRef]

9. Mussatto, S.I.; Roberto, I.C. Acid hydrolysis and fermentation of brewer's spent grain to produce xylitol. J. Sci. Food Agric. 2005, 85, 2453-2460. [CrossRef] 
10. Carvalheiro, F.; Duarte, L.C.; Medeiros, R.; Gírio, F.M. Xylitol production by Debaryomyces hansenii in brewery spent grain dilute-acid hydrolysate: Effect of supplementation. Biotechnol. Lett. 2007, 29, 1887-1891. [CrossRef]

11. Mussatto, S.I.; Dragone, G.; Roberto, I.C. Ferulic and p-coumaric acids extraction by alkaline hydrolysis of brewer's spent grain. Ind. Crop. Prod. 2007, 25, 231-237. [CrossRef]

12. Bartolomé, B.; Gómez-Cordovés, C.; Sancho, A.; Diez, N.; Ferreira, P.; Soliveri, J.; Copa-Patiño, J.L. Growth and release of hydroxycinnamic acids from Brewer's spent grain by Streptomyces avermitilis CECT 3339. Enzym. Microb. Technol. 2003, 32, 140-144. [CrossRef]

13. Moreira, M.M.; Morais, S.; Barros, A.; Delerue-Matos, C.; Guido, L.F. A novel application of microwave-assisted extraction of polyphenols from brewer's spent grain with HPLC-DAD-MS analysis. Anal. Bioanal. Chem. 2012, 403, 1019-1029. [CrossRef] [PubMed]

14. Ou, S.; Kwok, K.C. Ferulic acid: Pharmaceutical functions, preparation and applications in foods. J. Sci. Food Agric. 2004, 84, 1261-1269. [CrossRef]

15. Priefert, H.; Rabenhorst, J.; Steinbüchel, A. Biotechnological production of vanillin. Appl. Microbiol. Biotechnol. 2001, 56, 296-314. [CrossRef] [PubMed]

16. Heinonen, M.; Rein, D.; Satue, M.T.; Huang, S.; German, J.B.; Frankel, E.N. Effect of Protein on the Antioxidant Activity of Phenolic Compounds in a Lecithin-Liposome Oxidation System. J. Agric. Food Chem. 1998, 8561, 917-922. [CrossRef]

17. Friedman, M.; Jürgens, H.S. Effect of $\mathrm{pH}$ on the stability of plant phenolic compounds. J. Agric. Food Chem. 2000, 48, 2101-2110. [CrossRef]

18. Buranov, A.U.; Mazza, G. Extraction and purification of ferulic acid from flax shives, wheat and corn bran by alkaline hydrolysis and pressurised solvents. Food Chem. 2009, 115, 1542-1548. [CrossRef]

19. Ferri, M.; Happel, A.; Zanaroli, G.; Bertolini, M.; Chiesa, S.; Commisso, M.; Tassoni, A. Advances in combined enzymatic extraction of ferulic acid from wheat bran. New Biotechnol. 2020, 56, 38-45. [CrossRef]

20. Long, L.; Ding, D.; Han, Z.; Zhao, H.; Lin, Q.; Ding, S. Thermotolerant hemicellulolytic and cellulolytic enzymes from Eupenicillium parvum 4-14 display high efficiency upon release of ferulic acid from wheat bran. J. Appl. Microbiol. 2016, 121, 422-434. [CrossRef]

21. Moreira, M.M.; Morais, S.; Carvalho, D.O.; Barros, A.A.; Delerue-Matos, C.; Guido Luís, F. Brewer's spent grain from different types of malt: Evaluation of the antioxidant activity and identification of the major phenolic compounds. Food Res. Int. 2013, 54, 382-388. [CrossRef]

22. Lin, S.H.; Juang, R.S. Adsorption of phenol and its derivatives from water using synthetic resins and low-cost natural adsorbents: A review. J. Environ. Manag. 2009, 90, 1336-1349. [CrossRef] [PubMed]

23. Dávila-Guzman, N.E.; Cerino-Córdova, F.J.; Diaz-Flores, P.E.; Rangel-Mendez, J.R.; Sánchez-González, M.N.; Soto-Regalado, E. Equilibrium and kinetic studies of ferulic acid adsorption by Amberlite XAD-16. Chem. Eng. J. 2012, 183, 112-116. [CrossRef]

24. Conidi, C.; Rodriguez-Lopez, A.; Garcia-Castello, E.M.; Cassano, A. Purification of artichoke polyphenols by using membrane filtration and polymeric resins. Sep. Purif. Technol. 2015, 144, 153-161. [CrossRef]

25. Javanmardi, J.; Kubota, C. Variation of lycopene, antioxidant activity, total soluble solids and weight loss of tomato during postharvest storage. Postharvest Boil. Technol. 2006, 41, 151-155. [CrossRef]

26. Gouveia, S.; Castilho, P.C. Antioxidant potential of Artemisia argentea L'Hér alcoholic extract and its relation with the phenolic composition. Food Res. Int. 2011, 44, 1620-1631. [CrossRef]

27. Meneses, N.G.T.; Martins, S.; Teixeira, J.; Mussatto, S.I. Influence of extraction solvents on the recovery of antioxidant phenolic compounds from brewer's spent grains. Sep. Purif. Technol. 2013, 108, 152-158. [CrossRef]

(C) 2020 by the authors. Licensee MDPI, Basel, Switzerland. This article is an open access article distributed under the terms and conditions of the Creative Commons Attribution (CC BY) license (http://creativecommons.org/licenses/by/4.0/). 